\title{
¡Aquí nadie es viejo! Usos e interpretaciones del Programa Centro del Adulto Mayor-EsSalud en un distrito popular de Lima*
}

\section{Gabriela Ramos Bonilla}

Grupo de Investigación de Edades de la Vida y la Educación - EVE

Pontificia Universidad Católica del Perú

\section{RESUMEN}

Este artículo analiza la forma en que son usados e interpretados los servicios del programa Centros del Adulto Mayor - CAM del Seguro Social en Salud por los usuarios y profesionales que lo ejecutan en un distrito popular del sur de Lima. Sobre la base de investigación etnográfica, se muestra la forma en que una política construye una "forma de vejez ideal» promovida a través de los servicios que ofrece. Lo planteado por el programa no es asumido de manera pasiva por los profesionales que lo implementan en el ámbito local. Ellos reinterpretan sus lineamientos en función de sus sentidos comunes y experiencias, lo cual genera grandes contradicciones, así como una reproducción parcial de prejuicios relacionados con la vejez. Por otro lado, los usuarios utilizan el programa como mecanismo para afrontar crisis experimentadas en esta etapa de sus vidas, asi como para oponerse al discurso hegemónico que los destina a vivir una vejez que no los satisface. El CAM les ofrece estas

\footnotetext{
* $\quad$ Este artículo resume los principales hallazgos de mi tesis de licenciatura: «¡Aquí nadie es viejo!: usos e interpretaciones del Programa Centro del Adulto Mayor - EsSalud de Villa María del Triunfo y las experiencias de envejecimiento de sus usuarios». Esta fue sustentada en el año 2014 y premiada como mejor tesis de su especialidad en el mismo año por la Pontificia Universidad Católica del Perú.
} 
oportunidades, pero no pueden ser aprovechadas uniformemente ya que no todos los miembros cuentan con los recursos o capacidades para hacerlo, asi como también genera malestar al aislarlos conceptual y espacialmente denominándolos «adultos mayores».

Palabras clave: vejez, envejecimiento, adultos mayores, programas sociales, Lima.

\title{
No one is old here! Uses and interpretations of services provided by a Senior Activity Center in a low-income urban district of Peru
}

\author{
SUMMARY
}

The article analyzes the uses and interpretations of the services of a Senior Activity Center program (Centros del Adulto Mayor-CAM) by its users and the professionals who direct it in a low-income urban district of Lima, Peru. Based on ethnographic research, and revealed the way a public policy builds an «ideal old age» which is promoted by their services. This is not passively assumed by the professionals who implement the program locally. They reinterpret their guidelines based on their common sense and experience which generates contradictions and a partial reproduction of prejudices related to old age. On the other hand, users use the program as a mechanism to deal with moments of crisis that were experienced at this stage of their lives. Also to oppose the hegemonic discourse of old age that doesn't satisfy them. The CAM offers these opportunities but they don't benefit all members uniformly because they don thave the same resources or capacity. The program also creates discomfort between these elders because it isolates them conceptually and spatially when it calls them «seniors».

Keywords: aging, population aging, elderly, social programs, Peru 


\section{INTRODUCCIÓN}

Es bien conocido que la población mundial atraviesa un proceso de envejecimiento poblacional ${ }^{1}$ que implica importantes consecuencias sociales e individuales. Hasta el año 2015 se calculaba que 12,3\% de la población global tenía edades por encima de los sesenta años, pero con el tiempo este grupo seguirá aumentando y en 2050 representará el 21,5\% (HelpAge, 2015).

HelpAge Internacional (2015) indica que América Latina está siguiendo la misma tendencia y es una de las regiones que envejecen más rápido ${ }^{2}$. Del mismo modo, la distribución por edades de la población peruana ha cambiado drásticamente en menos de un siglo. El Instituto Nacional de Estadística e Informática - INEI indica que en el año 1950 nuestra población era mayoritariamente joven y el grupo de personas adultas mayores ${ }^{3}$ era muy reducido. Actualmente esto ya

$1 \quad$ El envejecimiento poblacional es un proceso de cambio gradual en la estructura por edades de una población que se caracteriza por el aumento relativo en la proporción de personas de sesenta años y más y la disminución de los grupos de edades más jóvenes. Ello es producto de la disminución de las tasas de fecundidad y la mortalidad de la población en edad avanzada y el aumento de la esperanza de vida al nacer como consecuencia del desarrollo de los servicios de salud.

2 En el año 2000, la población latinoamericana estaba compuesta por 508 millones de personas y se calcula que en el año 2050 llegue a las 800 millones. Actualmente se considera que estos países jóvenes, o en estado de transición, en 2050 la mayoría serán sociedades envejecidas. Esto se debe a los importantes cambios que está experimentando la estructura de edades de nuestra región. En el año 2000 el grupo joven menor a los 15 años representaba $32 \%$ de la población total, pero para el año 2050 se reducirá al 20\%. Por el contrario, en 2000 el grupo de sesenta años a más equivalía al $8 \%$ de la población total, pero para el año 2050 representará 23\% (HelAge, 2015; Dulcey-Ruiz, 2015).

3 En el Perú se denomina «persona adulta mayor» a todo quien tenga sesenta años a más (ley 30490). Esto se debe a que se ha acordado en el ámbito internacional que el comienzo de la vejez en los países en vías de desarrollo se da a los sesenta años y en los países desarrollados a los 65, ya que la esperanza de vida al nacer y a las condiciones de vida son distintas de estos países (Dulcey-Ruiz, 2015). 
no es así: el $10 \%$ de la población peruana tiene más de sesenta años y para el año 2050 este grupo alcanzará el 22\%, siendo Lima - la capital del país - el espacio donde se concentrará la mayor cantidad ${ }^{4}$ de personas de este grupo etario (INEI, 2015).
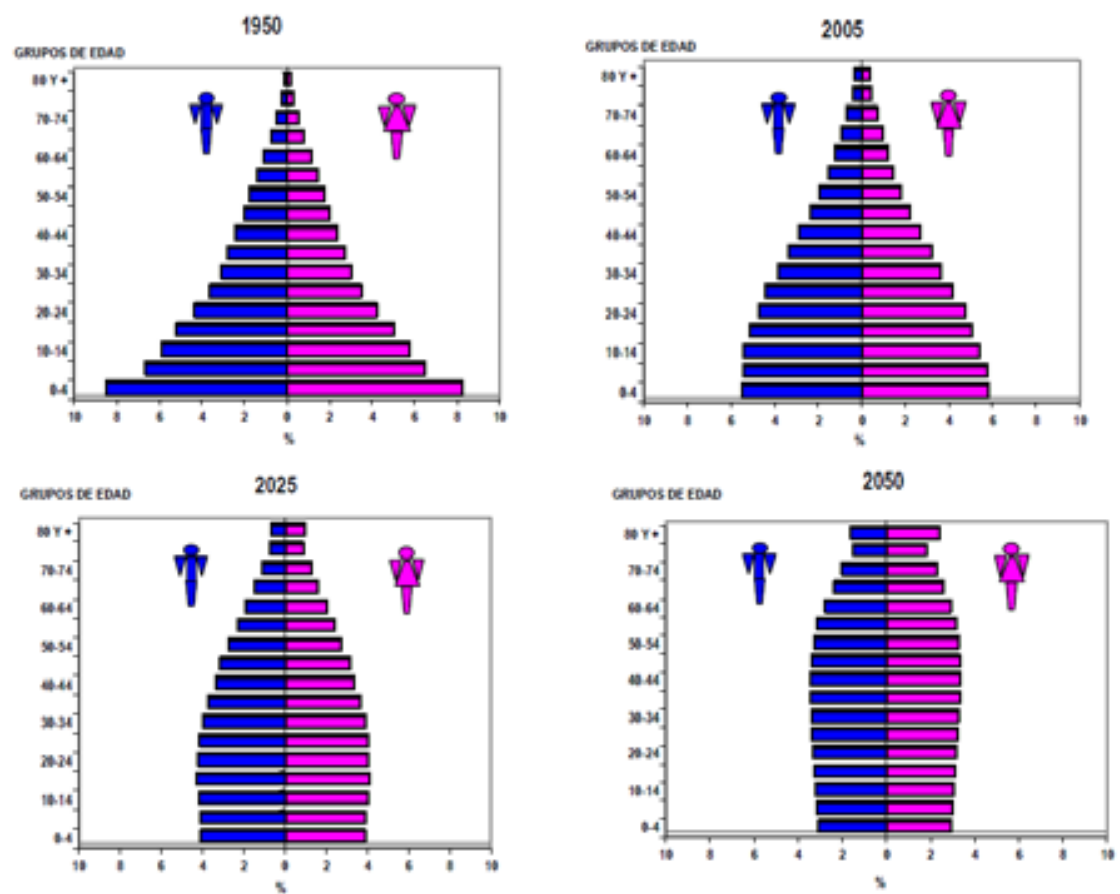

Imagen 1. Pirámides poblacionales del Perú (1950-2050). Fuente: INEI, 2009 (p. 29).

El envejecimiento de las sociedades es una de las revoluciones demográficas más importantes de nuestros tiempos y podría ser considerado un logro humano debido a que es la expresión del desarrollo económico y social. Los grandes esfuerzos de nuestras sociedades por controlar y disminuir la fecundidad, mejorar la calidad de vida de sus pobladores y las grandes innovaciones en nuestros sistemas de salud han generado que las personas podamos vivir vidas más largas y los grupos etarios más jóvenes se reduzcan. A pesar de ello, este fenómeno suele ser percibido política y económicamente como una «catástrofe mundial». Se discute si el envejecimiento poblacional generará el colapso de los sistemas

4 En Lima se concentra el 35\% de las personas mayores de sesenta años del país (INEI, 2015). 
de pensiones y de salud, si será el causante del final del Estado de Bienestar o si llevará a un conflicto generalizado entre generaciones por la utilización de los recursos (Pérez Díaz, 2011).

Esta preocupación se torna aún más crítica respecto de las regiones que cuentan actualmente con menos recursos, así como también mayores niveles de pobreza y desigualdad, como es el caso de América Latina. Este tipo de contextos pueden generar que grandes sectores de la población se encuentren en riesgo de experimentar situaciones de vulnerabilidad durante la vejez, así como también desafían la capacidad de los gobiernos para responder adecuadamente a estos cambios (Huenchuan, 2009).

Como producto de esta preocupación, desde hace ya un par de décadas distintas organizaciones de la sociedad civil peruana, así como múltiples investigaciones de corte demográfico y económico, han buscado comenzar a estudiar la población adulta mayor del país para poder predecir y controlar este fenómeno, así como plantear políticas que respondan a las necesidades de aquellos que se encuentran en extrema pobreza. Las principales problemáticas abordadas fueron justamente los bajos niveles de cobertura de los sistemas contributivos de pensiones y de salud de la población adulta mayor peruana ${ }^{5}$, lo cual generó debates sobre la necesidad de promover sistemas de pensiones no contributivas y sistemas de salud universales (Cáritas, 2009). Como producto de estas discusiones hemos comenzado a ser testigos de la creación de las primeras leyes, políticas y programas sociales en favor de esta población ${ }^{6}$.

5 El Perú se rige bajo un sistema de pensiones contributivas, constituido por un sistema público (Sistema Nacional de Pensiones - SNP) y otro privado (Sistema Privado de Pensiones - SPP). Debido a los elevados niveles de informalidad laboral, una proporción mínima de los trabajadores peruanos realiza contribuciones a algún sistema de pensiones durante su vida laboral, por lo cual durante la vejez se encuentra en un mayor riesgo de experimentar situaciones de precariedad, pobreza o la necesidad de seguir trabajando en condiciones adversas. Asimismo, existe un bajo acceso a los sistemas de salud y a la atención de calidad, así como hace algunos pocos años no existían políticas de salud enfocadas en las necesidades particulares de la población adulta mayor, quienes durante esta etapa de sus vidas tiene mayores gastos en salud debido a la aparición de enfermedades crónicas principalmente y generan una mayor demanda de estos servicios.

6 El MIMP ha elaborado tres Planes Nacionales para las Personas Adultas Mayores (2002-2006; 2006-2010 y 2013-2017) y una Ley de las Personas Adultas Mayores que actúan como marco bajo el cual se organizan y se crean las políticas sociales para la población envejecida del país. Se han creado iniciativas que buscan el envejecimiento saludable: lineamientos de atención y servicios de salud geriátricos en Minsa y EsSalud (Tayta Wasi, SIS, Padomi) y centros comunitarios que promueven estilos de vida saludables (en EsSalud los CAM; en municipalidades los CIAM; en Inabif los CEDIF; en el Minsa los Círculos del Adulto Mayor). A pesar de que 
Mientras la vejez está cobrando importancia en el ámbito de las políticas públicas, hasta el momento los estudios desde las ciencias sociales son escasos e insuficientes. Esta temática usualmente ha sido abordada desde una perspectiva macrosocial y cuantitativa, dejando de lado la exploración del efecto que tiene este fenómeno demográfico en los individuos, sus vidas cotidianas, sus comunidades y la sociedad desde una perspectiva microsocial (Robles Silva, Vázquez Palacio, Reyes Gómez y Orozco Mares, 2006).

Los estudios cualitativos realizados por sociólogos y antropólogos peruanos aún resultan escasos y son producto de esfuerzos individuales en lugar de un interés real por la academia local. Estos buscan poner a los adultos mayores en el centro de atención y dejar de pensar en ellos solo como informantes privilegiados debido a su conocimiento acerca de la historia de sus comunidades (Ramos, 2013). Privilegian «la mirada de los ancianos respecto de cómo viven y se mueven en el mundo social y cotidiano a partir de ser conceptualizados como personas envejecidas» (Robles et al., 2006). Las temáticas abordadas por estas investigaciones han sido bastante diversas ${ }^{7}$, pero ninguna de ellas se ha enfocado en estudiar los nuevos programas sociales creados para personas adultas mayores en el país.

El estudio de intervenciones gerontológicas es más común entre psicólogos y trabajadores sociales, quienes miden cuantitativamente los beneficios del uso de esos programas en la salud mental y desarrollo social de las personas mayores. Considero que el estudio cualitativo y etnográfico de estas instituciones es de gran importancia y utilidad, ya que generaría conocimiento valioso para su mejoramiento progresivo, ayudando a comprender con mayor profundidad sus dinámicas internas, limitaciones y conflictos. Asimismo, estos estudios cuestionan el imaginario común según el cual las personas en instituciones para adultos mayores constituyen un grupo homogéneo, sin agencia ni poder de decisión, y

aún no se cuenta con un sistema de pensiones no contributivas y universales, se han generado iniciativas que buscan mejorar la situación económica de PAM en situación de pobreza extrema (Pensión 65 del Midis) y capacitar a las que desean seguir trabajando (programas de inserción laboral del Mintra). También hay programas que buscan brindar educación básica (EBA en el Minedu), viviendas a quienes se encuentran en situación de calle (Vida Digna), revalorar sus saberes (Saberes Productivos - Midis) y protección en casos de violencia (CEM y Cerpam del MIMP).

7 Estas temáticas fueron: la educación superior y el uso de tecnologías en la vejez, representaciones sociales en la publicidad (López, 2009; López, 2010), las masculinidades en el envejecimiento (Ramos, 2005), trayectorias y proyectos de vida de ancianos institucionalizados (Matassini, 2014), roles sociales y estatus en zonas rurales (Nué, 2000), sistemas de cuidado familiar y abandono de personas adultas mayores en zonas rurales de Ayacucho (Cuadros, 2004; Leinaweaver, 2010). 
en cambio, resaltan la importancia de considerar las perspectivas y prácticas distintas de estos actores para comprender cabalmente el quehacer cotidiano de estas intervenciones. Por último, es necesario que el crecimiento de este tipo de intervenciones esté acompañado de una mirada crítica que analice los nuevos discursos y prácticas sobre la vejez que son promovidas y recreadas a través de estos servicios, así como también la forma en que impactan de manera individual en las búsquedas de nuevas identidades y caminos que emprenden quienes están envejeciendo en esta nueva etapa de sus vidas.

En ese sentido, examino una sede del programa social para personas adultas mayores, conocido localmente como Centro del Adulto Mayor - CAM, ubicado en un distrito popular al sur de Lima. Este es un programa pionero en su tipo ya que fue creado por el Seguro Social Peruano (EsSalud) en 1982 para sus pensionistas jubilados, quienes en su mayoría corresponde a personas de clase media baja que han trabajado de manera formal como obreros o empleados en contextos urbanos. El programa atiende a asegurados mayores de sesenta años y que pueden desempeñar sus actividades cotidianas de manera autónoma, ya que se encuentran física y mentalmente saludables ${ }^{8}$. Se rigen bajo un sistema de cogestión ${ }^{9} \mathrm{y}$ buscan ser espacios de encuentro generacional y atender los principales problemas del envejecimiento, como el alejamiento del núcleo familiar, la soledad, problemas de salud físicos y emocionales, etc. Ofrecen talleres gratuitos de corte educativo, artístico y físico-deportivo, así como también asesorías nutricionales, psicológicas y atención médica primaria. Realizan eventos mensuales, paseos y viajes para sus miembros.

El distrito donde realicé esta investigación es Villa María del Triunfo, un espacio urbano de bajos recursos que se encuentra al sur de Lima. Originalmente era una zona árida y desértica que fue ocupada por jóvenes migrantes de las zonas rurales del país durante los las décadas de 1950 y 1960, reconocida como distrito

8 El programa no ha sido pensado para personas con mayores niveles de dependencia o discapacidad y no contempla actividades que estas personas puedan realizar, personal o infraestructura adecuada para su atención. Estos programas suelen implementarse en antiguas casas o espacios no necesariamente acordes con las necesidades de esta población, debido a la falta de presupuesto. Por ejemplo, el CAM en donde se realizó esta investigación anteriormente era un depósito de madera que fue habilitado y amoblado para la realización del programa. Además, hasta la fecha no existen programas de ocio o socialización para personas mayores con dependencia física o mental en el país, lo cual las convierte en un grupo aún más olvidado y marginado.

9 Esto implica la gestión compartida del centro y el cofinanciamiento de diversas actividades entre usuarios y la profesional responsable del CAM como representante de EsSalud. Cada centro tiene un grupo de ocho o nueve personas mayores voluntarias que desempeñan actividades de organización en coordinación con la profesional encargada de esta institución en la zona. 
en 1961. Junto con sus pobladores y sus incansables esfuerzos por hacerlo un buen lugar donde vivir, el distrito creció y envejeció. En la actualidad es el distrito con mayor cantidad de personas mayores del sur de Lima ${ }^{10}$.

Luego de una vida de lucha por contar con servicios básicos tales como agua, luz, desagüe y escuelas para sus hijos, sus primeros pobladores ahora reclaman servicios para las personas mayores como ellos. Debido a la falta de interés del gobierno por esta población durante las dos décadas pasadas, las personas adultas mayores de esta comunidad decidieron crear distintas organizaciones independientes que buscaban identificar y atender las necesidades de este grupo etario, brindándoles servicios educativos y de ocio. La principal se llama Asociación Club de Jubilados de VMT ${ }^{11}$. En el año 2009, el Seguro Social peruano decidió crear el Centro para Adultos Mayores en el que hice mi investigación, lo cual fue considerado por los miembros de la asociación un triunfo y una respuesta a sus demandas. Esta apertura generó que la mayoría de integrantes de la asociación se trasladaran al CAM, ya que eran pensionistas del Seguro Social, mientras que algunos que no pertenecen a este sistema de pensiones continúan en esta agrupación. Así, comenzaron a existir servicios para esta población que ya no eran manejados por las personas mayores de la comunidad. A pesar de ello, estas personas siguen manteniendo un rol fundamental en la organización y financiamiento del servicio. Actualmente, este CAM tiene seis años y cuenta con aproximadamente 630 inscritos.

Además de este CAM y de la asociación, en el distrito existen otros servicios para personas mayores ${ }^{12}$ que, aunque deberían atender a poblaciones más vulnerables de la zona que no tengan acceso a programas del Seguro Social peruano, en la práctica convocan y ofrecen servicios a quienes ya se encuentran atendidos. Esto se debe a que se trata de un grupo de personas más fácil de ubicar y contactar,

10 En el año 2014, Villa María del Triunfo tenía una población total de 441239 habitantes, de los cuales 39433 son personas mayores de sesenta años (8,9\% del total). Es el distrito con la mayor cantidad de personas mayores de la zona sur de Lima. Más de la mitad de estas personas no completaron su educación primaria $(55,2 \%)$ y el $12,8 \%$ es analfabeto. El $56,8 \%$ no cuenta con jubilación.

11 Este tipo de organizaciones autogestionadas de personas mayores no ha sido estudiado en nuestro país, pero se han encontrado evidencias etnográficas de este tipo de organizaciones en otros espacios marginales, como el estudiado por Yohko Tsuji en Nueva York (Tsuji, 2009).

12 Asociaciones independientes que agrupan una cantidad de miembros muy pequeña. La Municipalidad de VMT cuenta con un área que ejecuta el Plan Nacional del Adulto Mayor; a pesar de ello, solo realizan actividades bastante desarticuladas, como un taller de tai chi y algunos eventos a las que se convoca a las asociaciones existentes. El policlínico de EsSalud tiene talleres y charlas a los que asisten personas mayores. 




Imagen 2. Ingreso al Centro del Adulto Mayor de Villa María del Triunfo Fuente:

Registro fotográfico propio.

al estar ya organizados. Ello ha generado competencia entre programas, duplicación de esfuerzos y falta de atención a poblaciones más vulnerables que se encuentran en zonas más alejadas, tienen mayores problemas económicos, o sufren de fuertes problemas físicos que los vuelven dependientes de otros miembros de su familia.

El objetivo de esta investigación fue analizar la forma en que son usados e interpretados los servicios de este programa por los usuarios y profesionales que lo ejecutan en el CAM. Como explica N. Long (2001), todo programa está conformado por actores sociales que deben ser entendidos como sujetos con agencia. Estos interpretan y actúan sobre la realidad de diferentes maneras, por lo que su forma de relacionarse con la institución y sus miembros no siempre sigue una misma lógica. Estas perspectivas y prácticas distintas conviven en un mismo espacio, por lo que al interactuar entre sí se pueden generar dinámicas de negociación, acomodación o lucha.

En ese sentido, quise conocer los lineamientos originales de este programa y analizar el tipo de vejez que promueve, así como la manera en que la propuesta institucional era adoptada, interpretada y ejecutada diariamente por los profesionales de esta sede. Del mismo modo, examiné las formas en que los usuarios entendían y experimentaban la vejez, así como también las maneras de dar uso a 
los servicios ofrecidos por el programa y los significados que estas actividades tienen en sus vidas cotidianas. En el quehacer del CAM, las distintas visiones de los actores interactúan y entran en conflicto, por lo que se negocian constantemente los objetivos, usos y significados establecidos por la institución.

Para el desarrollo de esta investigación, realizada durante los años 2013 y 2014, se optó por una metodología cualitativa y se utilizaron diversas técnicas de recojo de información como las entrevistas en profundidad semiestructuradas, observación participante, registro audiovisual y revisión de documentación interna del programa. Para la selección de informantes se realizó un tipo de muestreo no probabilístico e intencional. Se entrevistó a todos los profesionales del CAM presentes durante el período de trabajo de campo, proveedores de servicios cercanos para personas adultas mayores y usuarios del programa de distinto sexo, edad (estratos: de 61-70; 71-80; 81 en adelante) y tipo de participación ${ }^{13}$.

\section{El programa y sus implementadores}

El Centro del Adulto Mayor - CAM es una intervención que busca «mejorar el proceso de envejecimiento» de sus usuarios, mostrándoles que la vejez puede $\mathrm{y}$ debe ser un período de desarrollo personal en el que ejerzan sus derechos plenamente, sean vistos y se sientan capaces de aportar a sus familias y la sociedad, que cuiden su cuerpo y su salud para ser sujetos autónomos, y que valoren su riqueza cultural. Esta «vejez ideal» puede ser alcanzada a través de su participación en el programa, que ha sido diseñado bajo un «modelo gerontológico» que busca identificar aquellas áreas más problemáticas durante la vejez para actuar sobre ellas y darles nuevos sentidos positivos. El modelo consiste en una reflexión teórica o discursiva que integra cuatro enfoques o marcos conceptuales. Estos dan forma a una propuesta práctica de cuatro programas que contienen una gran variedad de eventos, campañas de sensibilización, así como talleres físicos, artísticos y educativos.

13 Entrevisté a dos profesoras y a la directora del CAM; a dos proveedores de servicios para PAM de la zona, así como también a diecisiete personas adultas mayores con edades comprendidas entre los 61 y 88 años, ocho de las cuales eran mujeres y nueve hombres. Debido a que se trata de un grupo focalizado por el programa, todos los varones contaban con una pensión por jubilación por haber sido obreros o empleados, mientras que las mujeres contaban con una pensión por viudez. Asimismo, todos gozaban de una buena salud y eran autosuficientes. 
Tabla 1. Enfoques, programas y talleres del CAM

\begin{tabular}{|c|c|c|}
\hline \multicolumn{3}{|c|}{ Modelo gerontológico } \\
\hline Enfoques & Programas & Talleres \\
\hline $\begin{array}{l}\text { Enfoques de: } \\
\text { Derechos }\end{array}$ & $\begin{array}{l}\text { Estilos de vida para un } \\
\text { envejecimiento activo }\end{array}$ & $\begin{array}{l}\text { Talleres de educación emocional, memo- } \\
\text { ria, autocuidado, artísticos, cultura física, } \\
\text { actualización cultural. servicios de } \\
\text { turismo social, huertos familiares, come- } \\
\text { dor, eventos deportivo-recreativos. }\end{array}$ \\
\hline $\begin{array}{l}\text { Envejecimiento } \\
\text { activo } \\
\text { Diversidad }\end{array}$ & intergeneracional & $\begin{array}{l}\text { campañas informativas para sensibilizar } \\
\text { a la comunidad en general sobre el enve- } \\
\text { jecimiento. }\end{array}$ \\
\hline $\begin{array}{l}\text { cultural } \\
\text { Género }\end{array}$ & $\begin{array}{l}\text { Red de soporte } \\
\text { familiar }\end{array}$ & $\begin{array}{l}\text { Campañas informativas para promover el } \\
\text { trato digno en la familia y entorno social. }\end{array}$ \\
\hline & Microemprendimiento & $\begin{array}{l}\text { Talleres ocupacionales y de microem- } \\
\text { prendimiento. }\end{array}$ \\
\hline
\end{tabular}

Fuente: Información obtenida del libro Los Centros del Adulto Mayor como modelo gerontológico social. La experiencia de EsSalud (EsSalud, 2012) y revisión de documentos internos de la institución. Elaboración propia.

El modelo brinda lineamientos generales que todo CAM debe seguir, pero también busca ser flexible para que los profesionales que dirigen cada una de las sedes puedan adaptar sus servicios a las necesidades, problemática y cultura particulares de la población con la que trabajen. Por ello, la forma en que será ejecutado en programa depende de la manera en que estas personas lo adopten e interpreten en función de las percepciones que tengan de la vejez, de la lectura que hagan de la población con la que trabajan, así como de su capacidad, conocimientos y experiencias previas.

Las profesionales del CAM de Villa María del Triunfo que fueron entrevistadas eran egresadas de las especialidades de trabajo social, educación primaria y danzas folklóricas, y ninguna de ellas había sido instruida para trabajar con personas adultas mayores durante su formación profesional ${ }^{14}$. Ingresar a trabajar con esta población fue un reto para ellas, ya que al interactuar constantemente con estas personas notaron que sus necesidades y capacidades eran distintas de las de otros grupos de edad y, debido a ello, era fundamental crear una metodología de trabajo adaptada a estas particularidades. Así, su imagen de la vejez y

14 Esto no solo se debió a que ellas no imaginaban que trabajarían con esta población en el futuro, sino a que no existían espacios de formación en este tema. 
la dinámica de sus sesiones de clase se fueron formando simultáneamente. Ellas percibieron que las personas durante la vejez, en comparación con la niñez o la juventud, «ya están formadas» y deterioradas física y psicológicamente, por lo que ya no pueden adquirir nuevas capacidades: solo pueden aspirar a mantener o recuperar las que poseen.

Al principio me dio temor, porque era una población que tenía limitaciones: cada quien tiene sus propios males. No es como trabajar con niños, que son sanos, saludables [...] Artrosis, osteoporosis, diabetes, osteopenia, diversidad de enfermedades. Me informé de las dolencias que había, cómo eran, tenía que saber para no dañarlos [...] El adulto mayor, a medida que va pasando el tiempo, va perdiendo capacidades, hay que enseñarles desde cero. En cambio los niños y jóvenes están en la etapa de formación de sus capacidades, pero el adulto mayor no, ellos ya están formados (profesora de danzas folklóricas).

Ha bajado su razonamiento. Van recordando acá. Depende también de la edad, a mayor edad es más difícil de que te puedan comprender, hay que trabajar y enfatizar bastante con ellos a fin de recordarles siempre para que no olviden (profesora de educación primaria).

Debido a esto, las profesoras explicaron que las clases no debían buscar que se adquirieran a la perfección los conocimientos impartidos - lo cual consideraban que no siempre era posible debido a las limitaciones de estas personas- sino más bien actuar como terapias físicas o emocionales para aminorar los males que los aquejan:

El trabajo era completamente distinto, es más pausado, danzas más suaves. Es una terapia física, porque va a tratar de que sus capacidades se vuelvan a renovar. [También es una] terapia de relajación [...] Siempre les digo: «yo no vengo a sacar artistas, yo vengo a que ustedes la pasen bien y se olviden de los problemas que tengan». Los hago gritar y gritar es una terapia excelente, «lo que no grita en casa, grita acá» [...] Se interrelacionan con otros compañeros, cuentan sus problemas, se conocen (profesora de danza folklórica).

Vienen con bastante inquietud de aprender, con esas ganas de pasar un momento agradable, porque no todo es clase, también compartimos el café para poder relajarnos un momento y después trabajar. Ellos participan, salen a la pizarra, trabajamos en grupos para que les permitan integrarse más, vienen acá, conversan (profesora de educación básica).

Esta lectura de la vejez se tornó aún más crítica al analizar contextos sociales adversos, como los del distrito en que se ubica el CAM. La directora del centro realizaba diagnósticos anuales de la situación socioeconómica de los usuarios, 
concluyendo que era una población en situación de riesgo y vulnerable debido a las malas relaciones que mantenían con sus familias, sus bajos niveles educativos y económicos ${ }^{15}$.

En ese sentido, las implementadoras reinterpretaban los objetivos y forma de entender la vejez del CAM y, en consecuencia, sus perspectivas daban un sentido y forma particular de ser implementada a la propuesta institucional. Debido a ello, la participación de las personas adultas mayores de las actividades y talleres del CAM implicaba no solo que estos adquieran nuevos conocimientos o habilidades, sino que adopten nuevos discursos sobre la vejez que los ayuden a reinterpretar la etapa vital que atravesaban, así como también nuevos comportamientos, estilos de vida, etc. Este programa en su conjunto deseaba brindar a los usuarios la posibilidad de transformarse y adoptar una manera ideal de vivir la vejez.

Aquellos elementos que les causaban malestar y vergüenza sobre la vejez debían ser resignificados y convertidos en nuevas posibilidades o ganancias. La cantidad de años que una persona tenía era un motivo de celebración, ya que simbolizaba los logros de su vida. A pesar de que se consideraba que la vejez implicaba deterioro físico, este podía controlarse a través del ejercicio y la adopción de estilos de vida saludables. La pérdida de ciertos roles o relaciones laborales y familiares debía ser vista como una posibilidad de disfrutar el tiempo libre, de nuevas actividades de ocio y amistades. Por ello, se solía decir a las mujeres — quienes eran la mayoría de los usuarios del CAM — que debían negarse a cuidar de sus nietos o seguir ejerciendo labores domésticas.

Estos discursos sobre la vejez estaban presentes de diversas maneras en la institución: se repetían oralmente en reuniones, estaban escritos en murales y eran transmitidos a los usuarios a través de talleres y cursos. Los talleres ofrecidos en este CAM — computación, educación primaria, danzas folklóricas peruanas, manualidades y gimnasia ${ }^{16}$ — incluían siempre dinámicas o contenidos

15 Este centro concentraba una población de 630 personas inscritas, de las cuales 363 eran mujeres. La mayoría de mujeres se concentraba en los grupos más jóvenes (60-69 años), mientras que los hombres se concentraban en los grupos de mayor edad (70-80 a más). La mayoría de la población era migrante de primera generación y tenía grados educativos generalmente bajos (23\% de las mujeres no tenía instrucción). La mayoría se encuentra casada y las personas viudas representan el segundo grupo más numeroso. Todos recibían una pensión mensual, aunque bastante pequeña.

16 Los talleres fueron elegidos con la finalidad de responder al perfil de los usuarios. El personal del CAM consideró adecuado ofrecer danzas folklóricas por su origen migrante, un taller de educación básica por el nivel de analfabetismo de los usuarios, y uno de manualidades para elaborar objetos que luego puedan vender y obtener ingresos. 
que reproducían estas ideas con el fin de que fueran adoptadas por los participantes. En ese sentido, no solo había una forma ideal de vivir la vejez sino también una forma ideal de utilizar los servicios del programa. Por otro lado, los eventos masivos servían como momentos para reforzar estos discursos y prácticas mediante la premiación de aquellos miembros que encarnaban este ideal de vejez.

No todos los usuarios del CAM usaban sus servicios o adoptaban sus discursos de manera integral, lo cual era preocupante para la directora y las profesoras. Por ello, se crearon estrategias para incentivar la participación otorgando privilegios a quienes lo hacían: poder de decisión, ser priorizados cuando hay pocos cupos para un paseo gratis, ser premiados en eventos, etc. Estas diversas maneras de usar el programa dependían de la forma de entender y vivir la vejez, así como sus necesidades, recursos y capacidades actuales de los usuarios.

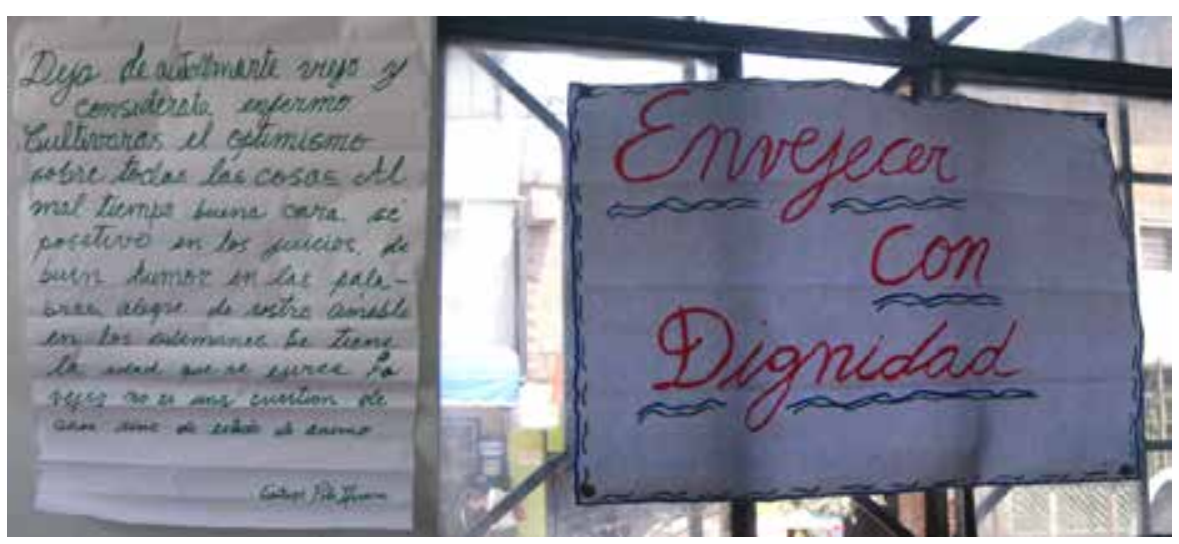

Imagen 3. Papelógrafos del taller de educación básica que ambientaban el aula del $\mathrm{CAM}^{17}$. Fuente: registro fotográfico propio.

\section{Experiencias de envejecimiento y rutinas diarias de los usuarios}

Las personas que asistían al centro vivían muy cerca unas de otras, pero no necesariamente experimentaban vejeces similares. Como lo plantean las teorías

17 Transcripción de papelógrafo: «Deja de autollamarte viejo y considerarte enfermo. Cultivarás el optimismo sobre todas las cosas. Al mal tiempo, buena cara. Sé positivo en los juicios, de buen humor en las palabras, alegre en el rostro, amable en los ademanes. Se tiene la edad que se ejerce. La vejez no es una cuestión de años sino de estado de ánimo». 
del ciclo de vida, estas distinciones son resultado de la influencia de múltiples dimensiones sociales sobre trayectorias de vida individuales, tales como el acceso a la educación, el lugar donde vivieron, su etnicidad, situación familiar, laboral y el género (Osorio, 2006; Dulcey-Ruiz, 2015). En ese mismo sentido, la vulnerabilidad y desigualdad experimentada durante la vejez por algunas personas debe ser entendida no solo como resultado de la edad que se tiene sino también como una acumulación de desventajas que se superponen a lo largo de la vida en estas distintas dimensiones (Koehn y Kobayashi, 2011).

Los entrevistados nacieron entre los años 1920 y 1950, por lo general en zonas rurales andinas pobres del país donde vivieron durante su niñez ${ }^{18}$. Sus padres eran agricultores, les enseñaron a cosechar la tierra, pastar el ganado y hablar en quechua. Nacer en estos espacios y en contextos de gran exclusión social implicó no contar con la mayoría de servicios básicos, pero sobre todo tener posibilidades limitadas de acceso a la educación. En general, las escuelas en sus lugares de origen eran escasas y lejanas, la calidad no era buena y los niños eran requeridos por sus familias para actividades laborales, por lo cual la mayoría de los entrevistados solo había cursado los primeros años de educación primaria ${ }^{19}$. Estudiar para las mujeres era más complicado, debido a que sus familias no consideraban que fuera necesario educarla, pues estaban destinadas a cumplir con tareas domésticas y a sus roles de madre en el futuro.

Tenía catorce años y no estaba estudiando y mi mamá y mi papá no me ponían en la escuela, estaba un poco lejos. Dentro de mí pensaba «cómo voy a estar así, debo aprender algo porque "chacrero" no más como mi papá voy a sufrir». Vacas tenía bastante mi papá, yo era el pastor (Nicolás, 80 años).

A mi madre solo le alcanzaba para darnos la primaria; éramos cinco, pues [...] Como yo siempre fui muy servicial, una vez que crecí - a los doce años-, yo me hice cargo de la casa. Y como he tenido ese don de tener buena sazón, entonces mi mamá no me soltó (Otilia, 62 años).

Durante las décadas de 1940 y 1950, los entrevistados migraron a la ciudad de Lima buscando una mejor vida y formando parte de lo que Matos Mar (1986)

18 Lugares de nacimiento mencionados: sierra de Lima, Piura, Huancavelica, Cajamarca, Áncash, Apurímac, Ayacucho, Junín, Ica, Moquegua y Arequipa.

19 Niveles educativos de los entrevistados: uno sin educación formal; cuatro con primaria incompleta; cinco con primaria completa; tres con secundaria incompleta; uno con secundaria completa; dos con educación superior incompleta; uno con educación superior completa. Seis de las nueve mujeres se encuentran en los niveles más bajos (sin educación, primaria completa e incompleta). 
llamó el «desborde popular». El ser migrantes no educados limitó y condicionó sus posibilidades de ingreso al mercado labora ${ }^{20}$. Los hombres encontraron trabajo formal como obreros o empleados de servicio que mantuvieron durante toda su adultez, desempeñando el rol de proveedores dentro de las familias que formaron en la ciudad. En cambio, la mayoría de las mujeres se casaron, tuvieron entre dos y nueve hijos y asumieron el cuidado del hogar y la crianza. Algunas entrevistadas explicaron que sus esposos les prohibían trabajar, pero la mayoría se desempeñaba informalmente en actividades como la venta de comida, sastrería o el cuidado del hogar y niños de otras personas para apoyar a la economía familiar.

La vejez, al igual que las anteriores etapas de sus vidas, está marcada fuertemente por diferencias de género. En el aspecto laboral y económico, los hombres se jubilaron luego de cuarenta años de servicio cuando tenían entre 52 y 66 años y empezaron a recibir una pensión ${ }^{21}$. Luego de ello, siguieron trabajando en otras labores, como la atención de negocios familiares y venta de productos por un promedio de quince años a más. Paulatinamente dejaron de trabajar y se desligaron de sus ámbitos y redes laborales para comenzar a vivir de sus pensiones.

Tabla 2. Trabajos luego de jubilarse

\begin{tabular}{lll}
\hline Entrevistados & Tipo de trabajo & Trabajos posteriores \\
\hline Esteban & & Bodega \\
Eusebio & Negocio familiar & Librería \\
Santiago & Puesto del mercado \\
\cline { 2 - 3 } Nicolás & Trabajo independiente & Albañil \\
Eduardo & & Efectivo de seguridad \\
Victorino & & Músico de misas de cocina \\
\hline
\end{tabular}

Fuente: entrevistas a usuarios del CAM. Elaboración propia.

20 Matos Mar describe el mercado laboral limeño como dividido entre empleos para «profesionales», los cuales representaban solo el 32,6\% de la PEA y empleos para sectores populares de migrantes como «obreros, trabajadores asalariados en servicios, vendedores ambulantes, artesanos, desocupados y trabajadores del hogar» (Matos Mar, 1986).

21 Los entrevistados trabajaron de manera formal. Las instituciones donde trabajaban estaban obligadas por la ley a afiliar a sus trabajadores al Sistema Nacional de Pensiones nacional - SNP y hacer que estos contribuyan con el $10 \%$ de su sueldo a su fondo de pensiones mensualmente. Las mujeres, en cambio, no cuentan con esta pensión debido a que trabajaron informalmente. 
En cambio, las mujeres no obtuvieron pensiones de jubilación al no haber accedido a trabajos formales. Claramente esta situación de mayor vulnerabilidad económica es resultado de una serie de desventajas educativas y laborales acumuladas a lo largo de sus vidas. Las mujeres casadas dependían de las pensiones de sus maridos, mientras que las viudas y separadas estaban obligadas a seguir realizando actividades informales remuneradas, depender del apoyo económico de sus hijos o de las pensiones de viudez. Por ejemplo, Martha — una viuda de 73 años — nunca había trabajado fuera de casa porque su marido pensaba que las mujeres debían de atender solo el hogar. Por eso, ella no tenía una pensión propia, pero sí cuatro hijos que velaban por su salud y necesidades económicas. En cambio, Adelina —una mujer separada de 73 años - se casó, pero nunca tuvo hijos propios. Su marido, quien era mujeriego y la maltrataba, le hizo criar a dos de sus hijas que había tenido con otra mujer. Su esposo trabajaba, pero el dinero nunca alcanzaba en casa, por lo que Adelina a veces conseguía «chambitas» como cocinera de algún evento del barrio. A los 42 años se separó y siguió trabajando en labores eventuales, como el préstamo de dinero, la venta de comida o la venta de tejidos que ella confeccionaba. Actualmente sigue realizando estas labores debido a que no tiene una pensión, y a que su exesposo y las niñas que crió no la apoyan económicamente ${ }^{22}$.

En el aspecto familiar, la viudez y el crecimiento de los hijos supusieron grandes cambios que afectaron de manera distinta tanto a hombres como a mujeres. Al ser tradicionalmente las esposas quienes se ocupaban de las tareas domésticas, enviudar significó para los hombres tener que adoptar estos roles no ejercidos anteriormente, a menos que otra mujer de su familia compartiera esta carga con ellos $^{23}$. Por ejemplo, Nicolás y Jacinto — ambos viudos- debían ocuparse del hogar y el cuidado de sus hijos jóvenes y nietos pequeños:

Mi hijo está enfermo porque le ha pasado accidente en la columna. De ahí no camina, para en cama no más. Su esposa trabaja en una casa para que coman los chicos, se va tempranito, cerca de las diez de la noche está llegando. Ahora, yo me encargo de los chicos. Yo más que mujer hago doble trabajo, porque no está mi esposa, pues. Ahora yo tengo que hacer todos los servicios, lavar, limpiar la casa, todo, lavo ropa. Primero sufría bastante pero luego he cerrado los ojos y tengo que aprender al golpe (Jacinto, 79 años).

22 Adelina no contaba con una pensión de jubilación, por lo cual no debería haber accedido a los servicios del CAM. A pesar de ello, la directora del centro la dejó ingresar debido a que ella se mostró muy insistente. Este es uno de los pocos casos similares que fueron observados.

23 El sociólogo Miguel Ramos (2005) también observó que los varones viudos o con parejas enfermas «no tenían más remedio que realizar actividades estereotípicamente femeninas» en su estudio sobre masculinidad y envejecimiento. 
Cuando no está mi hija o si salen, ya yo me cocino. Mi hijo viene a cenar y tengo que esperarlo con la comida. No todos los hombres cocinan, pero yo esa costumbre he tenido siempre. Cuando estaba mi señora también, a veces ella estaba haciendo una cosa y yo otra al lado. Le decía «cómo hago esto», «haz así y así». «Qué tal está mi almuerzo», le digo. «Ta' rico, ta” bien». Así parábamos (Nicolás, 80 años).

Por el contrario, para las mujeres estos cambios supusieron una disminución en sus cargas domésticas cotidianas. Como explica Cassie (2011), esta es una etapa que brinda la posibilidad de explorar nuevas identidades, además de ser madres o esposas. Sin embargo, también aparecen nuevas labores de cuidado alrededor de los nietos, lo que implicaría continuar con el rol de «crianza transgeneracional de toda la vida» (Ramos, Vera-Tudela y Cárdenas, 2009) y una amenaza a esta nueva libertad.

Durante las conversaciones entre las mujeres que acudían al centro, el cuidado de los nietos era normalmente motivo de discusión y fastidio. Muchas de ellas repetían algunos de los discursos que habían escuchado en clases diciendo que «ya no estaban para cuidar a nadie» aunque no siempre sentían que fuera posible negarse a ayudar a sus hijas, quienes no contaban con los medios para contratar a una niñera y, además, debían salir a trabajar todo el día fuera de casa. Este es el dilema de Victoria, de 72 años:

Un nieto yo lo he criado de la edad de un mes hasta que ha tenido siete años. Yo iba, venía, lo lavaba, lo llevaba al colegio, le ponía la ropa y le limpiaba la casa a mi hija, volvía para almorzar, volvía a recogerlo a su casa y volvía a mi casa. Claro, hay momentos en que yo le digo «hijita, ya no ya. Yo ya los he criado a ustedes, ahora les toca». En un caso posible en que mi hija trabaje, sí lo he hecho, señorita. No le puedo negar, es mi hija; si ella trabaja es para darle un pan a sus hijos. Toda abuela quiere que ellos surjan.

Es un difícil dilema que puede llevar a acuerdos, de manera explícita o no, basados en el intercambio del trabajo de las abuelas por el cuidado y apoyo que pueden recibir de sus hijos en el momento actual o en el futuro. Este tipo de intercambio intergeneracional de bienes y servicios circula en ambos sentidos y es bastante común en las familias de pocos recursos debido a que suelen tener como principal sistema económico y de seguridad a dichas redes sociales (Freidenberg, 2000; Ramos, Vera-Tudela y Cárdenas, 2009). Por último, la disminución de actividades laborales y familiares, que en otros tiempos ocupaban todas las horas del día, ha generado períodos de tiempo libre en las rutinas cotidianas de los entrevistados. Durante un promedio de seis horas al día estos realizan actividades al interior de 
sus hogares, como ver televisión, escuchar música o leer periódicos. Sin embargo, generalmente estos períodos no son disfrutados, pues resultan abrumadores al ser percibidos como momentos «en que no se hace nada» y se está solo.

Tabla 3. Cambios en trayectorias y rutinas durante la vejez

\begin{tabular}{|c|c|c|c|}
\hline Tipos de cambios & Género & Cambios en trayectorias & Rutinas cotidianas \\
\hline \multirow{2}{*}{$\begin{array}{l}\text { Laboral- } \\
\text { económico } \\
\text { (jubilación y } \\
\text { pensiones) }\end{array}$} & Hombres & $\begin{array}{l}\text { Se jubilan, tienen una } \\
\text { pensión, se desligan de } \\
\text { roles y redes laborales. }\end{array}$ & $\begin{array}{l}\text { Ningún hombre } \\
\text { entrevistado seguía } \\
\text { trabajando. }\end{array}$ \\
\hline & Mujeres & $\begin{array}{l}\text { No se jubilan ni tienen } \\
\text { pensión. } \\
\text { Buscan otras fuentes de } \\
\text { ingresos: apoyo familiar } \\
\text { o seguir trabajando. }\end{array}$ & $\begin{array}{l}\text { Cinco mujeres } \\
\text { entrevistadas trabajaban } \\
\text { informalmente. }\end{array}$ \\
\hline \multirow{2}{*}{$\begin{array}{l}\text { Familiar- } \\
\text { doméstico } \\
\text { (viudez y } \\
\text { alejamiento de } \\
\text { hijos) }\end{array}$} & Hombres & $\begin{array}{l}\text { Enviudar implica que } \\
\text { asuman nuevos roles } \\
\text { domésticos. }\end{array}$ & $\begin{array}{l}\text { Seis viudos realizaban } \\
\text { todas las tareas } \\
\text { domésticas. }\end{array}$ \\
\hline & Mujeres & $\begin{array}{l}\text { Mayor libertad: nuevas } \\
\text { identidades. Menor carga } \\
\text { doméstica (+nietos). }\end{array}$ & $\begin{array}{l}\text { Todas realizaban las } \\
\text { tareas domésticas }(3 \mathrm{~h} \\
\text { promedio). }\end{array}$ \\
\hline Tiempo libre & $\begin{array}{l}\text { Hombres } \\
\mathrm{y} \\
\text { mujeres }\end{array}$ & $\begin{array}{l}\text { Disminución de } \\
\text { actividades laborales } \\
\text { y familiares y el } \\
\text { distanciamiento de } \\
\text { círculos sociales } \\
\text { cercanos. }\end{array}$ & $\begin{array}{l}\text { Períodos de tiempo libre: } \\
6 \text { h promedio. «No se } \\
\text { hace nada» y se está solo. }\end{array}$ \\
\hline
\end{tabular}

Elaboración propia a partir de entrevistas sobre trayectorias de vida y rutinas diarias de los usuarios de CAM.

Usos e interpretaciones de los servicios ofrecidos en el CAM por los usuarios

Los miembros del CAM no usan el programa dentro de una misma lógica o por iguales motivos. Estas particularidades se deben a las diferentes necesidades que buscan satisfacer, a través del uso del centro, el significado que den a las acciones realizadas dentro de él, así como los recursos físicos, educativos o económicos con los que cuentan.

Se observó que había dos grupos distintos de miembros. El primero utilizaba de manera selectiva e instrumental el programa y no se sentía parte de él. 
Solo asistían a actividades que les resultaban atractivas, como talleres, viajes o eventos especiales, pero luego se retiraban por no tener tiempo o no desear involucrarse más profundamente con el programa. Este grupo reunía a la mayoría de usuarios inscritos del CAM.

En cambio el segundo grupo mostraba un mayor interés por formar parte del centro: asistían diariamente por períodos prolongados y apoyaban en la organización de distintas actividades. Este grupo estaba conformado principalmente por mujeres y hombres viudos que, pese a vivir solos y tener más tareas laborales y domésticas, decidían levantarse entre 4 y 5 de la mañana para realizar sus obligaciones y luego poder disfrutar del programa sin sentir que descuidaban su $\operatorname{hogar}^{24}$. En el caso de las mujeres, esto último es visto como una prioridad, por lo que sentían mayor presión en cumplir con sus obligaciones domésticas y no ser sancionadas socialmente.

Este es el caso de Lucy, quien les contaba a sus amigas del CAM sobre sus estrategias para escapar de casa y de su esposo, que era una persona muy antisocial: «Él sólo quiere estar sentado en el patio leyendo el periódico; no sabes cuántas veces le he dicho que venga, iyo me vengo sola!». Se levantaba muy temprano en la mañana para cocinar el almuerzo del día y luego le decía a su esposo: «Me voy, te lo calientas, ¿ah?», y se iba «corriendo» a su clase de baile. Riendo le decía a sus compañeras: « $¡ Y$ Ya no me puede decir nada, ya!». Lucy había aprendido a mantener la familia y el centro en una relación de «equilibrio» mediante muchos esfuerzos, pero otras usuarias no siempre lo lograban y eran vistas por las demás como «malas mujeres» por descuidar a su familia o como malas usuarias del CAM por no asistir regularmente.

24 Existen diversas razones que podrían explicar el alto nivel de participación e interés de las personas viudas. Las que se han considerado principales son que la muerte de las parejas suele generar una gran crisis en estas personas, por lo cual desean afrontar esta situación a través del ingreso al CAM, donde pueden llenar sus días con actividades nuevas y ampliar sus redes sociales. Particularmente en el caso de las mujeres viudas, una mayoría explicaba que la viudez - aunque es una de las pérdidas más grandes que afrontaron en esta etapa de sus vidas - las hizo sentir mayor libertad, ya que sus difuntos maridos solían ser muy represivos. Por lo tanto, el ingresar al CAM las hizo sentir que pueden tener la oportunidad de explorar nuevas aficiones, amistades, e incluso aventurarse a tener nuevas parejas. 


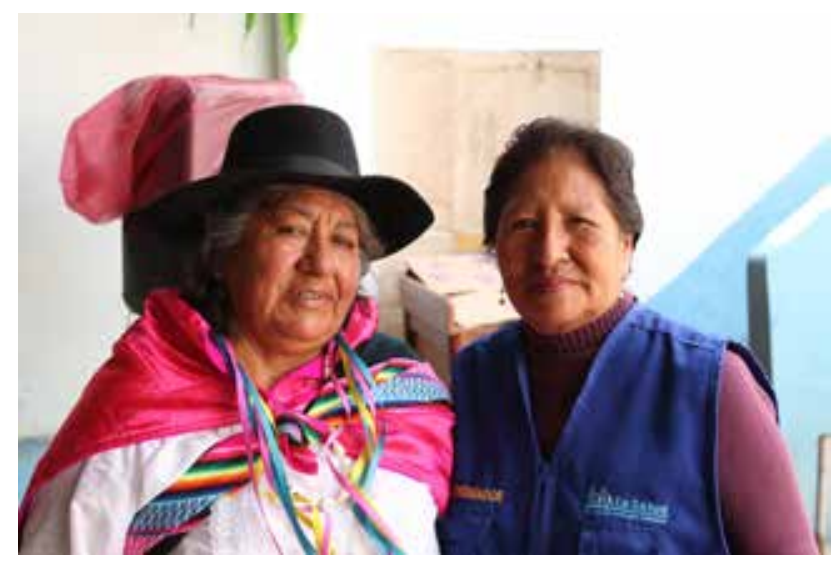

Imagen 4. Usuarias del CAM que ejercían cargos de coordinación.

Fuente: Fotografía propia

Por otro lado, incluso al interior de este grupo se observaron diferentes formas de usar el programa. El género fue un factor de diferenciación importante, tanto en el uso cotidiano de los servicios como en el ingreso al programa. La mayoría de los miembros eran mujeres ${ }^{25}$, posiblemente debido a la promoción de discursos de igualdad de género desde el centro y a que los servicios ofrecidos (como el baile, la gimnasia o talleres de manualidades y tejido) eran percibidos por la mayoría de hombres de la zona como actividades «femeninas». Sobre el uso cotidiano del programa, los hombres preferían realizar actividades de recreación libre, como jugar naipes, billar, y conversar o leer, por lo que los implementadores del CAM consideraban que no hacían uso «correcto» del programa. Estas actividades no solo se salían de lo planificado por el programa o lo considerado saludable, sino también, en algunos casos, no eran consideradas moralmente adecuadas, por lo que se les llamaba constantemente la atención. Con tono bromista pero sancionador, la directora les decía «ahí están de nuevo con el vicio». Incluso —al ver que yo jugaba con ellos - les decía «cuidadito con estarla corrompiendo». Esta frase recurrente sugería que no se deseaba que ellos realizaran esa actividad, asociada con los juegos de apuestas y no con el ejercicio de la agilidad mental o la socialización, como los usuarios del CAM lo hacían.

25 Esto es algo bastante común en los CAM del país: el 66\% de sus usuarios corresponde a mujeres. Existen casos anómalos que indican tener una población masculina casi igual o mayor a la de las mujeres: CAM de Huancavelica, Puno y Juliaca, Pasco, Amazonas, Lambayeque, Tumbes y Madre de Dios (EsSalud, 2012). 
En ese sentido, los implementadores solían comparar el comportamiento de las mujeres y hombres que participaban en el centro y las usuarias eran constantemente puestas como ejemplo debido a que se acercaban más al ideal de vejez que este programa buscaba. Por ello, se considera que la vejez ideal propuesta por el CAM parece asociar los comportamientos y actitudes tradicionalmente asociadas a la femineidad con características saludables y positivas, mientras que las asociadas a la masculinidad tradicional con el vicio y la enfermedad, actitudes que el centro no puede ni debe promover.

Tener menores recursos económicos también influyó en el uso del programa. Este tipo de personas presentó mayores dificultades en costear su participación en las actividades organizadas por el centro. Generalmente los cursos ofrecidos eran gratuitos para los usuarios, pero algunas actividades, como los paseos a las afueras de la ciudad, los viajes a otras provincias del país y los almuerzos de conmemoración de una fecha especial implicaban que los usuarios pagaran una cuota para ser costeados.

Por otro lado, algunas personas acudían al programa para adquirir habilidades artísticas que pudieran usar con fines laborales, o incluso buscando trabajar en él. Por ejemplo, Adelina acudía a los talleres de tejido y manualidades del centro para aprender nuevas técnicas. Estos conocimientos eran usados para elaborar chalinas y adornos, los cuales vendía a otros usuarios del CAM o a conocidos del barrio. Una usuaria trabajaba como cocinera en el comedor, y otra fotografiaba actividades y viajes realizados en el centro para luego vender esas fotos a sus compañeros.

Por último, si bien los usuarios del CAM contaban con una condición de salud que les permitía mantener su autonomía, algunos tenían problemas físicos menores que les dificultaban usar los servicios ofrecidos por el programa y socializar. Quienes presentaban problemas auditivos tendían a aislarse, al no poder participar de conversaciones con facilidad o seguir las instrucciones en los talleres. Jacinto (79), por ejemplo, tenía problemas para escuchar a los demás y solía sentarse solo a armar rompecabezas durante varias horas, sin conversar con nadie, para luego irse a casa. Los demás usuarios no intentaban hablar con él porque la conversación se hacía muy complicada.

Asimismo, los problemas en las articulaciones impedían a algunos usuarios participar en talleres físicos. Martha (73) y Esteban (78) eran fanáticos de las danzas tradicionales y las habían bailado durante toda su vida, pero ya no podían hacerlo. Martha sufría de artritis y bailar le ocasionaba mucho dolor, pero a pesar de eso, a veces las ganas la ganaban y asistía a alguna clase. Esteban ya no se animaba a bailar; por un lado, ahora le cuesta mucho mover la parte izquierda 
de su cuerpo debido a que hace algunos años tuvo un derrame cerebral jugando fútbol, y por otro, aunque hubiese podido bailar con gran esfuerzo, le daba vergüenza hacerlo porque su desempeño no era igual.

Finalmente, se indagó acerca de la manera en que los usuarios daban significado al programa y se encontró que este estaba ligado fuertemente con la forma en que entendían la vejez. Arber y Ginn (1996) dividen la edad en tres dimensiones diferentes: la edad cronológica, social y fisiológica. Los entrevistados eran conscientes de la cantidad de años que tenían, pero consideraban que a su edad cronológica había personas que eran «viejas» y otras que no.

Tabla 4. Autopercepción de la vejez

\begin{tabular}{lll}
\hline Edad cronológica & Edad social & Edad fisiológica \\
\hline & $\begin{array}{l}\text { Es una forma de actuar que } \\
\text { puede elegirse. }\end{array}$ & Es inevitable a largo plazo. \\
& «Ser viejo»: indigno, triste y & «Ser viejo»: estar enfermo y ser \\
«Envejecer es un & solitario. & «Yo»»: aún saludable e \\
proceso natural». & «Yo»: pleno, juvenil, alegre y & independiente. \\
& sociable. & \\
\hline
\end{tabular}

Elaboración propia con las percepciones de la vejez de los entrevistados. Basada en la tipología de la edad de Arber y Ginn (1996).

Ser «viejo» era una manera particular de sentirse y actuar que consideraban negativa y de la cual habían elegido alejarse adoptando formas «juveniles». Eran felices, vitales, se consideraban útiles y estaban rodeados de amigos, por lo tanto «no eran viejos». El centro tiene un papel central en la búsqueda por «no volverse viejo». Quienes le daban uso selectivo e instrumental al programa explicaban que no deseaban ser miembros activos porque era un lugar «para viejos» y que, según ellos, promovía la ociosidad; era donde las personas solitarias e inútiles van a pasar el día. Entrar a un CAM era para ellos asumir la categoría de «viejo» y ser limitado e identificado por ella.

En cambio, quienes lo usaban con regularidad pensaban en este espacio como un lugar que promovía formas de comportarse que los hacía sentir «rejuvenecidos», más extrovertidos y útiles, incluso considerando las actividades que realizaban en el CAM como su «nuevo trabajo».

Ser adulto mayor es una cuestión mental. Es cuestión de actitud; tenemos que dignificar esta edad interesante y hacerla más plena, más juvenil, por 
lo menos en la mente y el espíritu, que nos interrelacionemos más, que no estemos andando agachados, pateando el piso, a veces la actitud hace mucho (Victorino, 69 años).

Bueno, señorita, yo sí me siento adulta mayor sino que trato de cambiar, de hacer cosas para no estar sentada en la casa y quedarme (hace un gesto como estático, de tristeza con la cara), porque hay personas que no quieren venir y están sentadas en su casa y más se enferman. Así que acá yo no me siento como adulta mayor, yo me siento, qué le digo, alegre, me gusta lo que estoy haciendo para seguir viviendo un poquito más (Teresa, 78 años).

Aprender y experimentar cosas nuevas dentro del centro también era asociado con el hecho de sentirse joven. En este lugar podían revivir antiguos intereses, experimentar cosas como estudiar, tener grupos de amistad, nuevas relaciones amorosas o viajar, actividad que no pudieron realizar anteriormente porque tenían que trabajar duramente o cuidar de los hijos. Estas experiencias adquieren una mayor importancia para los usuarios durante la vejez debido a la proximidad de la muerte.

A pesar de ello, pertenecer a este espacio y tener que asumir ser calificados por la categoría «adulto mayor», haciendo énfasis en que son un grupo etario particular, generaba en ocasiones sensaciones de incomodidad entre los usuarios del programa y los hacía entrar en conflicto con esta etiqueta impuesta. A continuación presento un evento que presencié que ilustra estos conflictos y contradicciones.

Hace algunos años Pamo - quien tenía 72 años cuando lo conocí- se jubiló y sus hijos habían dejado la casa. Él y su esposa consideraron que había que buscar algo qué hacer e ingresaron al CAM. Pamo era una persona muy activa, le gustaba ofrecerse como voluntario para la organización de las actividades del centro. Él decía que todo esto lo hacía sentir «joven», porque era «útil» para los otros miembros de la institución: estaba ocupado, era respetado y pensaba que esto era como su «nuevo trabajo». Debido a su dedicación al centro, lo iban a premiar en una ceremonia en un enorme coliseo como «El mejor adulto mayor». Al terminar la ceremonia de premiación, los miembros del centro y yo estábamos conversando. De pronto, una señora del grupo le dijo a la esposa de Pamo: «iQué bueno que hayan nombrado a su esposo el mejor anciano!». Dorita, la esposa de Pamo, le respondió molesta que su esposo no era ningún viejo y la otra señora se disculpó, admitiendo que se había equivocado y que debió decir «el mejor adulto mayor», como le enseñaron en el centro. Dorita explicó de manera bromista: «Decir adulto mayor es la manera amable de decirle viejo a alguien». La otra señora soltó una risa nerviosa y respondió: «Es cierto, ¡acá no hay ningún viejo, todos somos chibolitos!». Pamo sabía que lo premiaban por ser un miembro 
importante en su comunidad y ser parte de ella lo hacía sentir reconocido, pero no quería ser calificado como «adulto mayor»: él no era ningún «viejo» (extracto de informe de trabajo de campo).

Por otro lado, el «ser viejo» también era considerado un estado físico de deterioro y dependencia. Los entrevistados gozaban de una buena salud pero pensaban que la dimensión física de la vejez es algo que no puede evitarse a largo plazo: solo puede retrasarse mediante el cuidado de la salud y el ejercicio, lo cual les parecía deprimente y era un motivo de preocupación constante. Por ello, los entrevistados parecían estar en una angustiosa lucha por mantener sus cuerpos saludables y evitar la enfermedad, o como dice Eusebio, no «oxidarse»:

El cuerpo es como una máquina y al envejecer uno le tiene que dar mantenimiento para que no se oxide [mientras dice esto mueve repetitivamente los hombros y los dedos]. [El cuerpo de las personas mayores es] como una máquina guardada va malográndose, oxidándose, entonces, uno tiene que tener cuidado de eso. Si una máquina tiene veinte años de uso, comienza a fallar, ¿no? (Eusebio, 88 años)

Por ello, los talleres de baile, gimnasia y campañas médicas eran fundamentales para los entrevistados, porque les brindaban la posibilidad de adoptar estilos de vida saludables mediante el ejercicio físico y mental. Otras actividades realizadas en el CAM también eran consideradas saludables: salir de casa e ir al centro, jugar con rompecabezas, hacer crucigramas o simplemente conversar y reír en grupo eran formas de ejercitar la mente y aliviar el estrés, así como era un espacio para compartir información médica.

La preocupación por no enfermarse gravemente o comenzar a presentar distintas discapacidades tiene bastante sentido en el contexto en el cual se encuentran estas personas. Si esto sucediera, ellos tendrían que depender de las relaciones familiares que hayan construido durante sus vidas, el criterio de sus hijos y su capacidad económica para apoyarlos o contratar personal que los atienda, ya que no existen programas estatales que se preocupen por el cuidado de las personas adultas mayores en situación de «dependencia física». Asimismo, si bien el CAM ofrece mecanismos para mantenerse saludable durante la vejez, este programa no está diseñado para atender a población con dependencias físicas o mentales $y$ el ideal de vejez que promueven no ofrece alternativas, ni pareciera que fuera posible de ser alcanzado por quienes sufren de estas aflicciones. Por estas razones, imaginar un futuro en que deban de ser cuidados por otros y ser internados en un «asilo» o casa de reposo es uno de los más grandes miedos para estas personas. 
Siempre estoy con la idea de pensar cómo será mañana o más tarde, esa es mi idea, mi pensamiento, estar pensando en mi futuro. A veces yo veo muchos ancianos que no pueden caminar, están con bastón y con las justas están moviéndose en su casa. Entonces, yo pienso que estar en esa situación va a ser terrible para mí, no voy a poder soportar, digo yo. Y voy a cometer alguna sonsera (Santiago, 74 años).

Por último, el CAM es considerado por los entrevistados como un lugar que los ayudó a afrontar dificultades que han atravesado durante los últimos años. Algunos expresaron que el enviudar, dejar de trabajar o algunos cambios familiares ocasionaron cuadros depresivos o problemas de salud física de los cuales pudieron salir gracias a su ingreso al CAM.

Estaba con la presión muy alta. Esa vez en emergencia vine con mi hija y mi hija justo ve que decía «CAM» y me dice «mami, ¿qué cosa es CAM? A ti te podemos inscribir acá», me dice [...] Bueno, gracias a mi hija que me trajo aquí y me inscribió. Y después poco a poco entré acá y comencé a hacer amigas. Te juro que desde esa vez que ingresé acá, ya no sé ni lo que es la presión emotiva ni nada por el estilo (Olga, 61 años).

[Cuando murió mi esposa] no tenía ánimo de vivir, pensaba mirando a la pared, intranquilo en mi casa. Entonces, mi hija me dijo, «papi, tienes que ir al adulto mayor». Por eso vine a inscribirme y me está sirviendo como una rehabilitación, converso con las amigas, para mí es mata-tiempo (Santiago, 74 años).

Algunos participantes explicaron que estar en su hogar los hace sentirse inútiles y solos. Asimismo, sus familias habían comenzado a actuar de manera violenta con ellos, lo cual los hacía sentir inseguros. En ese sentido, se percibe al centro como un refugio, un lugar seguro y propio donde se sienten queridos fuera de casa:

Si no vengo acá no hago nada, estoy leyendo en la sala y estoy solita. Qué voy a hacer ahí solita, me meto a mi cuarto. Ahí está el televisor, estoy mirando y me vence el sueño. Acá en el CAM hay amistades con quien conversar. Si están los viciosos (risas), los de las cartas, me quedo con ellos. Si no están, siempre hay un rompecabezas (Lucila, 84 años).

Yo vengo acá porque me entretengo, juego cartas con mis amigos. ¿Qué hago en mi casa? En mi casa no hago nada. Nada puedo hacer porque estoy mal. Tengo la columna con artrosis. No puedo agacharme bien, no puedo ni barrer. Me paro un rato y me duele, no puedo hacer nada. Yo no soy de estar ahí, sentado esperando, no (Esteban, 78 años). 


\section{CONCLUSIONES}

Cuando comencé a considerar estudiar un centro comunitario para personas adultas mayores, casi cada persona con la que compartí mis primeras inquietudes por el tema de la vejez opinaba que realizar este tipo de investigación sería deprimente, o al menos aburrido, y que implicaría el estudio de programas poco relevantes tanto para nuestra sociedad como para sus usuarios. Supuestamente, estas personas debían encontrarse en tales espacios no por voluntad propia sino porque no tenían nada más productivo que hacer, o porque alguien más los «dejó ahí» a pasar el tiempo. Mi experiencia fue casi completamente contraria a lo que se esperaba. Como les pasó en sus primeras investigaciones a antropólogos de la vejez a quienes admiro, como Jennie Keith (1982) o Jay Sokolovsky, este resultó ser un espacio de experiencias novedosas y gratificantes, además de historias divertidas, duras y apasionantes que me generaron una serie de nuevas interrogantes antropológicas y personales.

El estudio del envejecimiento de nuestras sociedades y el alargamiento de las vidas humanas se está volviendo necesario en nuestro país. En este contexto, la antropología debe tener un rol clave para comenzar a entender los efectos que este fenómeno demográfico tiene y tendrá en nuestra sociedad, cultura y las vidas de muchos peruanos que han envejecido o estamos en proceso de hacerlo (Kaufman, 1986). En ese sentido, debemos de tener un rol activo en la búsqueda de nuevas formas de actuar y entender esta nueva y larga etapa de la vida, así como también acompañar y colaborar con las nuevas instituciones creadas para personas adultas mayores que tienen un papel fundamental en el proceso de creación e introducción de nuevos roles positivos y significativos para la vejez. Los estudios etnográficos de este tipo de políticas públicas deben tener una mirada crítica, así como también propositiva, que genere información clave para su desarrollo e implementación, garantizando que propicien vejeces disfrutadas y que sean un verdadero momento de desarrollo personal (Freidenberg, 2000).

Esta investigación muestra la manera en que se construyen sentidos y prácticas asociados a la vejez dentro de una política pública para personas adultas mayores en la ciudad de Lima. Como se ha visto a lo largo de este artículo, lo planteado por la institución no es solo impuesto y asumido de manera pasiva por los actores involucrados en su implementación y uso; por el contrario, sus distintas maneras de interactuar y reinterpretar la propuesta del programa generan situaciones de conflicto, negociación y convivencia cotidiana. 
Los CAM del Seguro Social han construido un «ideal de vejez» que está contenido en su oferta de servicios. Los lineamientos formales de esta institución son reinterpretados por los funcionarios locales del distrito de Villa María del Triunfo, quienes los adaptan en función de sus perspectivas y experiencias acerca de la población con la que trabajan y su visión de la vejez. Las profesionales, que no habían sido formadas en el trabajo con esta población, recurren a su sentido común y discursos hegemónicos sobre la vejez que son característicos de las sociedades urbanas contemporáneas para poder enfrentar el reto que les plantea introducirse a un área laboral nueva.

En ese sentido, su práctica diaria presenta grandes contradicciones que, por un lado, incentivan a los usuarios a vivir una «mejor vejez», que solo sería posible alcanzar a través del consumo de bienes y servicios del programa y, por otro lado, su metodología y discursos siguen albergando prejuicios de los cuales les resulta difícil desligarse. Esto es evidente en su caracterización de la población envejecida con la que trabajan como «altamente vulnerable», en el sentido de que están en una situación de gran riesgo no solo por su edad sino por no contar con recursos económicos, educativos, redes de apoyo y por haberse deteriorado sus capacidades físicas y psíquicas, lo cual haría imposible para ellos generar estrategias para hacer frente a las dificultades que atraviesan.

Por el contrario, las historias de los usuarios del CAM reflejan su gran resiliencia ante la adversidad y capacidad de responder a los cambios y retos que implican envejecer. Las trayectorias de vida de los entrevistados no solo evidencian que los usuarios de este centro experimentan vejeces de características distintas (económicas, físicas, género, etc.) sino también que muchos de ellos han experimentado grandes cambios y crisis durante las últimas décadas de sus vidas asociados a la muerte de sus parejas, alejamiento y crecimiento de sus hijos y el dejar de ejercer roles sociales que antes eran claves en la definición de sus identidades. Asimismo, debido a su edad cronológica, la sociedad en la que viven los había destinado a ser percibidos como «viejos», lo que implicaba ser considerado como inútil, solitario, antisocial, dependiente y enfermo.

Los participantes de este estudio decidieron afrontar estas crisis y expresar que no se sentían o comportaban de la manera en que las estructuras dominantes de nuestra sociedad dicen que deberían hacerlo. En ese sentido, su entrada y uso de este centro - muy por el contrario a lo que normalmente se piensa- es una decisión consciente en donde el programa es utilizado como una herramienta con la cual generar una forma de vivir la vejez y ser percibidos por otros que los satisfaga. Ello demuestra que estas personas se relacionan con el programa de manera 
activa y creativa en función de sus propias necesidades e intereses, demostrando que no están volviéndose viejos pasivamente: a través de este programa, ellos buscan seguir creciendo y desarrollándose como personas en la vejez.

A pesar de que este programa ofrece a los entrevistados nuevas oportunidades que ellos valoran, existen conflictos con ciertos aspectos de esta iniciativa. Asistir al CAM a veces los hacía entrar en un conflicto, debido a que implicaba ser categorizados como «adultos mayores» y aislados conceptual y espacialmente de otros miembros más jóvenes de su entorno local y promover actividades de ocio para personas jubiladas. Esto generaba sensaciones de incomodidad tanto en los usuarios que asistían regularmente como en los que optaban por no hacerlo. Los que decidían no asistir consideraban que el CAM era un lugar para «viejos» y quienes acudían diariamente no se sentían cómodos con ser clasificados por su edad como un grupo distinto, pero permanecían en este programa porque los hacía sentir «rejuvenecidos» en tanto se sentían útiles, reconocidos, formaban nuevas redes sociales, etc. En ese sentido, estos espacios por un lado los limitan en su búsqueda por no ser clasificados, pero al mismo tiempo abren una nueva gama de posibilidades en la vejez.

Por otro lado, los usuarios no siempre tenían los deseos de utilizar el programa de manera integral ni tampoco los recursos económicos y capacidades físicas necesarios para hacerlo. Debido a ello, usan el servicio según sus capacidades y necesidades. Es por esta razón que existen grupos que cumplen con el ideal, los cuales son constantemente recompensados y otros que no. Es así que los implementadores, a pesar de haber buscado las maneras de que el programa se amolde a la realidad de la zona, tienen dificultades para que todos los usuarios participen y sean beneficiados por igual. Es necesario que este programa identifique las diferencias internas de la población local con la que trabajan para generar estrategias efectivas de inclusión social y diversifique su oferta de servicios.

\section{REFERENCIAS BIBLIOGRÁFICAS}

Arber, Sara y Ginn (1996). Mera conexión. Relaciones de género y envejecimiento. Madrid: Narcea.

Cáritas (2009). Envejecimiento con dignidad y derechos. Lima: PRAM y Cáritas.

Caissie, Linda (2011). The raging Granies: narrative construction of gender and aging. En Gary, Kenyon, Storying later life. Issues, investigations, and interventions in narrative gerontology (pp. 126-142). Oxford, UK: Oxford University Press. 
Cuadros, Julia (2004). Vejez y pobreza en el Perú: la visión de las personas de edad. Lima: CooperAcción.

Dulcey-Ruiz, Elisa (2015). Envejecimiento y vejez. Categorías y conceptos. Bogotá: Red Latinoamericana de Gerontología y Fundación Cepsiger para el Desarrollo Humano.

EsSalud (2012). Los Centros del Adulto Mayor como modelo gerontológico social. La experiencia de EsSalud. Lima: EsSalud.

Freidenberg, Judith (2000). Growing old in El Barrio. Nueva York: New York University Press.

HelpAge (2015). Índice Global de Envejecimiento, AgeWatch 2015. UK: HelpAge International.

Huenchuan (2009). Envejecimiento, derechos humanos y politicas públicas. Santiago de Chile: CEPAL.

INEI (2009). Perú: Estimaciones y proyecciones de población 1950-2050. Boletín demográfico $\mathrm{N}^{\circ} 36$. Lima: INEI.

INEI (2015). Estado de la población peruana 2015. Lima: INEI.

Kaufman, Sharon (1986). The Ageless Self. Sources of meaning in late life. Madison: The University of Winsconsin Press.

Keith, Jennie (1982). Old People, New Lives: Community Creation in a Retirement Residence. Chicago: University of Chicago Press.

Koehn, S., K. Kobayashi (2011). Age and ethnicity. En M. Sargeant (ed.), Age Discrimination and Diversity: Multiple Discrimination from an Age Perspective (pp. 132-159). Cambridge: Cambridge University Press. https://doi.org/10.1017/ cbo9780511777196.007

Leinaweaver, Jessaca (2010). Alejarse como proceso social: niños y ancianos 'abandonados' en Ayacucho. Anthropologica, 28, 139-162. Lima.

Long, Norman (2001). Development sociology. Actor perspectives. Londres: Routledge. https://doi.org/10.4324/9780203398531

López, Blanca (2009). Educación de nivel universitario para adultos mayores y perspectivas futuras en el marco de sus expectativas de estudio y trabajo y del envejecimiento galopante de la población. Lima: PUCP.

López, Blanca (2010). Modelos e imágenes del adulto mayor en la publicidad: los cambios que se vienen. Lima: PUCP.

Matassini, Silvana (2014). Re-adaptando proyectos de vida: personas adultas mayores viviendo en una institución pública en Lima, Perú. Lima: PUCP. 
Matos Mar, José (1986). Desborde popular y crisis del Estado. El nuevo rostro del Perú en la década de 1980. Lima: IEP.

Nué, Angélica (2000). Percepciones y autopercepciones de ancianos en la comunidad de Santa Cruz de Andamarca. Anthropologica, 18, 153-173. Lima.

Osorio, Paulina (2006). Abordaje antropológico del envejecimiento y el alargamiento de la vida. Santiago de Chile: Centro de Estudios sobre la Identidad Colectiva.

Pérez Díaz, Julio (2011). Envejecimiento demográfico. Apuntes de demografía. https:// apuntesdedemografia.com/envejecimiento-demografico/

Ramos, Gabriela (2013). Antropología de la vejez en el Perú: un vacío etnográfico. Anthropia, 11, 104-112. Lima.

Ramos, Gabriela (2014). ¡Aquí nadie es viejo!: usos e interpretaciones del Programa Centro del Adulto Mayor - EsSalud de Villa María del Triunfo y las experiencias de envejecimientos de sus usuarios. Tesis de licenciatura. Lima: Pontificia Universidad Católica del Perú.

Ramos, Miguel (2005). Masculinidad y envejecimiento. Lima: Asociación Peruana de Demografía y Población.

Ramos, Miguel, David Vera-Tudela y María Kathia Cárdenas (2009). Las personas adultas mayores y su contribución a la lucha contra la pobreza. Lima: Fondo de Población de las Naciones Unidas.

Robles Silva, Leticia, Felipe Vázquez Palacio, Laureano Reyes Gómez e Imelda Orozco Mares (2006). Miradas sobre la vejez. Un enfoque antropológico. México DF: El Colegio de la Frontera Norte y Plaza y Valdés.

Tsuji, Yohko (2009). An Organization for the Elderly, by the Elderly: A Senior Center in the United States. En J. Sokolovsky (ed.), The Cultural Context of Aging: Worldwide perspectives. Tercera edición. Westport, CT: Praeger Publishers. 